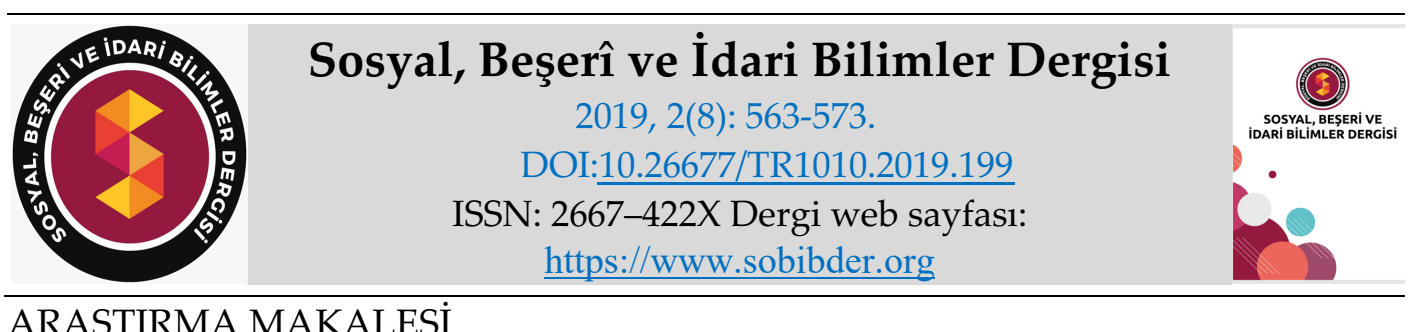

ARAȘTIRMA MAKALESI

\title{
Menkul Kıymet Yatırım Ortaklığı Sektörü Endeksinin Diğer BİST100 Sektör Endeksleri ile Risk Açısından Karşılaştırılması
}

\author{
Dr. Öğretim Üyesi Umut Tolga GÜMÜş, Aydın Adnan Menderes Üniversitesi, \\ İktisadi ve İdari Bilimler Fakültesi, Aydın, e-posta: ugumus@adu.edu.tr \\ ORCID: https://orcid.org/0000-0001-7363-8660
}

Prof. Dr. Yusuf KADERLİ, Aydın Adnan Menderes Üniversitesi, İktisadi ve İdari Bilimler Fakültesi, Aydın, e-posta: ykaderli@yahoo.com ORCID: https://orcid.org/0000-0001-6648-2602

Arş. Gör. Kemal ÖZDEMİR, Aydın Adnan Menderes Üniversitesi, İktisadi ve İdari Bilimler Fakültesi, Aydın, e-posta: kemal.ozdemir@adu.edu.tr ORCID: https://orcid.org/0000-0003-0644-6460

Arş. Gör. Ahmet Fatih KILIÇ, Aydın Adnan Menderes Üniversitesi, İktisadi ve İdari Bilimler Fakültesi, Aydın, e-posta: ahmet.fatih.kilic@adu.edu.tr ORCID: https://orcid.org/0000-0003-2484-9618

$\ddot{O} z$

Hisse senedi piyasaları, finansal piyasalar içerisinde risk düzeyi en yüksek olanlarından biridir. $\mathrm{Bu}$ yüzden yatırımclar genellikle bu piyasalarda işlem yaparken risklerini bertaraf edebilecek yaklaşımlarda bulunmaktadır. Bunun en etkili yollarından biri çeşitlendirme unsuru içeren varlıklara yatırım yapmaktır. Çeşitlendirme unsuru içeren varlıklardan biri de menkul kıymet yatırım ortaklıklarıdır. Bu çalışmanın amacı, menkul kıymet yatırım ortaklıklarının hisse senedi yatırımlarındaki çeşitlendirme katkısının tespit edilmesidir. Bunun için diğer sektörlerin taşıdığı finansal riskler ile menkul kıymet yatırım ortaklıklarının taşımış olduğu riskler tespit edilerek risk düzeylerine göre karşılaştırılmıştır. Elde edilen bulgular menkul kıymet yatırım ortaklıklarına yatırım yapmanın tek başına diğer sektörlerdeki hisselere yatırım yapmaktan daha az riskli olduğunu ortaya koymuştur. Yani riskten kaçan hisse senedi yatırımcıları açısından menkul kıymet yatırım ortaklığı sektörünün iyi bir seçenek olduğu görülmüştür.

Anahtar Kelimeler: Menkul Kıymet Yatırım Ortaklıkları, Portföy Yönetimi, Risk ve Getiri Makale Gönderme Tarihi: 24.06.2019

Makale Kabul Tarihi: 27.08.2019

\section{Önerilen Atıf:}

Gümüş, U.T., Kaderli, Y., Özdemir, K. ve Kılıç, A. F. (2019). Menkul Kıymet Yatırım Ortaklığı Sektörü Endeksinin Diğer BİST100 Sektör Endeksleri ile Risk Açısından Karşılaştırılması, Sosyal, Beşeri ve İdari Bilimler Dergisi, 2(8): 563-573.

C 2019 Sosyal, Beşerî ve İdari Bilimler Dergisi. 


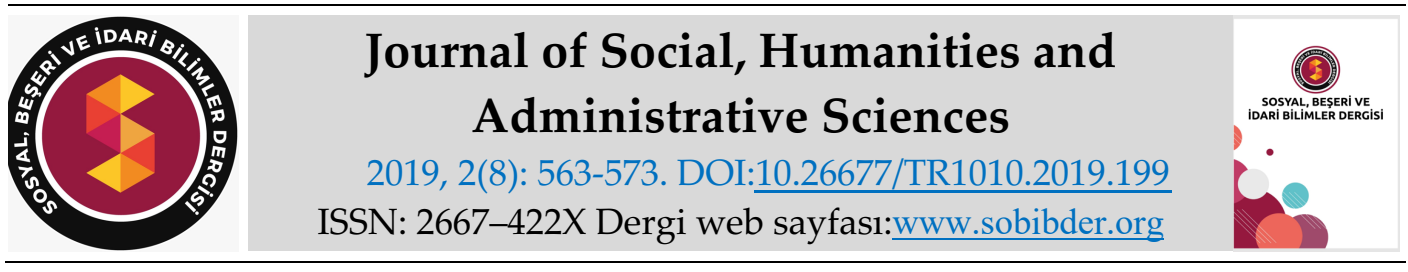

RESEARCH PAPER

\title{
In Framework of Risk Comparison of Securities Investment Associations Sectoral Indexes with Other Sectoral Indexes in ISE 100
}

Assistant Prof. Dr. Umut Tolga GÜMÜŞ, Aydın Adnan Menderes University, Faculty of Economics and Administrative, Aydın, e-mail: ugumus@adu.edu.tr ORCID: https://orcid.org/0000-0001-7363-8660

Prof. Dr. Yusuf KADERLI, Aydın Adnan Menderes University, Faculty of Economics and Administrative, Aydın, e-mail: ykaderli@yahoo.com

ORCID: https://orcid.org/0000-0001-6648-2602

Res. Asst. Kemal ÖZDEMİR, Aydın Adnan Menderes University, Faculty of Economics and Administrative, Aydın, e-mail: kemal.ozdemir@adu.edu.tr

ORCID: https://orcid.org/0000-0003-0644-6460

Res. Asst. Ahmet Fatih KILIÇ, Aydın Adnan Menderes University, Faculty of Economics and Administrative, Aydın, e- mail: ahmet.fatih.kilic@adu.edu.tr

ORCID: https://orcid.org/0000-0003-2484-9618

\begin{abstract}
Among financial markets, stock market is one of the riskiest markets. That is why investors need to be found in approaches that can eliminate their risks when trading in these markets. One of the most effective ways to do this is to diversify or invest in assets with diversification. One of the assets with diversification is securities investment trusts. The purpose of this study is to compare the financial risks carried by other sectors and the risk that the securities investment trusts are carried Forward and the risk levels between the mare compared with the high and low risk levels. This issue is of particular significance at the risk level in terms of being a natural diversification component of securities investment trusts in order to guide investors who want to invest in financial markets. The findings show that investing in securities investment trusts alone is less risky than investing in other sectors. It means that investment trusts are seen as ideal selection for investors who want to avoid from risk
\end{abstract}

Keywords: Securities Investment Trusts, Portfolio Management, Risk and Return

Received: 24.06.2019

Accepted: 27.08.2019

Suggested Citation:

Gümüş, U.T., Kaderli, Y., Özdemir, K. and Kılıç, A. F. (2019). In Framework of Risk Comparison of Securities Investment Associations Sectoral Indexes with Other Sectoral Indexes in ISE 100, Journal of Social, Humanities and Administrative Sciences, 2(8): 563-573.

(C) 2019 Sosyal, Beşerî ve İdari Bilimler Dergisi. 


\section{GíRiş}

Portföy, gerçek ve tüzel kişilerin sahip oldukları reel ve parasal varlıklardır. Aslında portföy kavramı tüm yatırım çeşitlerini kapsamakla birlikte genellikle anlaşılan veya ifade edilmeye çalışılan tahvil, hisse senedi, hazine bonosu gibi menkul kıymet yatırımlarının bileşimidir (Basık, 2011: 582). Bu varlıklardan elde edilecek getirinin artırılması etkin portföy yönetimiyle mümkündür. Tasarruf sahiplerinin, en uygun yatırım üzerinde odaklanması, elde edecekleri getiriyi yine en uygun bir şekilde değerlendirmek amacıyla yatırımlarında portföy oluşturma yoluna gitmesi düşük risk-yüksek getiri boyutları içerisinde makul olan seçeneklerden biridir.

Portföy yönetiminin amacı, risk ve getiriye göre hangi varlıkların ne oranda portföy içerisinde yer alacağı ve değişen piyasa koşulları içerisinde hangi varlıkların portföyden çıkarılacağının belirlenmesidir (Demirtaş ve Güngör, 2004:103). Piyasa belirsizliği, bilgi kaynağından gelen haberler ve diğer bazı faktörler riskin oluşmasında etkili olurken, bu riski yatırımlar içerisine yayarak azaltılması tasarruf sahipleri tarafından tercih edilmemektedir. Çünkü, Türk yatırımcılarının finansal piyasalar hakkında yeterli bilgi sahibi olmamaları, finansal okuryazarlık seviyelerinin \%24'lük bir oran ile düşük olması (Klapper vd., 2014:24) gibi nedenlerle, kısa vadede yüksek getiri beklentisi içerisinde olmaları, yatırımlarının risk düzeylerini artırmaktadır. Ancak, bu riskin azaltılması ve yayılması portföy çeşitlendirme stratejisi ile mümkündür.

Menkul kıymet yatırım ortaklıkları, bir portföyün işletilmesi üzerine kurulan anonim ortaklıklardır. Tek başına yatırım yapma bilgi ve becerisine, zamanına sahip olamayan tasarruf sahiplerinin tasarruflarını uzman kişilerin denetiminde birleştirilerek çeşitli alanlarda değerlendirmektedir (Sermaye Piyasası Kurulu, 2018). Dolayısıyla, birçok farklı finansal enstrümanlara yatırım yapmaları itibariyle menkul kıymet yatırım ortaklıkları, riskin azaltılması noktasında doğal bir çeşitlendirme olarak kabul edilebilir. Bu noktadan hareketle, tek bir iş kolunda faaliyet gösteren şirketlerin risk düzeylerinin doğal çeşitlendirme unsurunu içinde barındıran menkul kıymet yatırım ortaklıklarından yüksek olması beklenir.

$\mathrm{Bu}$ çalışmanın amacı, menkul kıymet yatırım ortaklıklarının taşımış oldukları riskin, diğer iş kollarının risklerine nazaran daha düşük olup olmadığının tespit edilmesidir. Buradan yola çıkarak, menkul kıymet yatıım ortaklıklarının portföy çeşitlendirmesinde önemli bir çeşitlendirme aracı (diversifier) olup olmadığının belirlenmesidir.

Çalışmanın birinci kısmında portföy, portföy çeşitlendirmesi, risk ve getiri konuları, ikinci kısımda ise menkul kıymet yatırım ortaklıkları, faaliyetleri, hukuki açıdan esasları ve portföy oluşturma konuları ele alınmıştır. Son bölüm ise uygulama bölümüdür. Bu bölümde öncelikle BIST'te yer alan bütün sektör endekslerinin 10 yıllık verileri esas alınarak, aylık bazda tarihi risk ve getiri oranları hesaplanmışır. Daha sonra, tüm sektör endekslerinin sonuçları, menkul kıymet yatırım ortaklığı sektör endeksi ile karşılaştırılarak değerlendirmeler yapılmıştır.

\section{PORTFÖY ÇEŞITLENDIRME, RISKK VE GETIRI}

Birçok finansal varlık, portföyü meydana getirebilir. Portföy çeşitlendirmesi, yatırımların tek bir varlık türünde toplanmasından ziyade riski azaltmak amacıyla farklı tür varlıklara dağıtılmasıdır. Geleneksel portföy yönetim mantığında, portföydeki değerli varlıkların sayısı ne kadar artırılırsa portföyün riski o derecede azaldığı görüşü hakimdir. Çeşitlendirme ile birlikte portföy riskinin sistematik riske yaklaştırılabileceği savunulmuştur (Aksoy, 2014:57). Markowitz bu riskin azaltılması konusunda farklı yatırım araçlarının yanı sıra aralarında negatif korelasyon bulunan yatıım araçlarının seçilmesi gerektiğini vurgulamaktadır (1952: 77). Portföy çeşitlendirmesi geleneksel portföy yaklaşımı ile ortaya çıkmasının yanında yapılan çalışmalar 
Markowitz ile birlikte artış göstermiştir (Kapusuzoğlu ve İbicioğlu, 2013:120) Bankalar, emeklilik fonları, sigorta şirketleri, ortak fonlar ve diğer finansal kurumlar portföy oluşturma konusunda yetki sahibidirler. Bu kurumlar kanunlara uygun bir şekilde çeşitlendirme yoluna gitmektedir (Brigham ve Houston, 1996:148).

Risk ve getiri kavramları, tek bir finansal varlığa bağlı olarak ölçülebildiği gibi, bir finansal varlık grubu yani bir portföy içinde de ölçülebilmektedir. Her ne kadar portföy riski finans yöneticisi için muhtemelen daha önemli olsa da genel risk kavramı tek bir varlık açısından daha kolay geliştirilmektedir. (Gitman, 1992:375).

\section{Portföy ve Çeşitlendirme}

Portföy, farklı risk düzeylerinde, tasarruf sahibi gerçek veya tüzel kişilerin farklı amaçlar doğrultusunda kullanabileceği, nakit, döviz, altın, tahvil, hisse senedi gibi yatırım araçlarının toplam değeridir. Ayrıca farklı finansal varlıkların bir araya getirilerek yeni bir finansal varlığın oluşturulması olarak da tanımlanabilmektedir. Temel amaç, bu varlıkların getirilerinin maksimum seviyeye çıkarılması ve bunu yaparken de risk faktörü göz önünde bulundurularak portföyün riskini düşürülmesidir. ABAY çalışmasında, portföyde hangi varlığın hangi oranlarda yer alacağını, risk ve getiri oranlarının ne şekilde ayarlanması gerektiğini de ana hedef olarak belirtmektedir (2013:175-194).

Portföy yönetimi ile ilgili olarak, çeşitli teoriler ortaya konulmuş olup bunun en bilindik yaklaşımlarından biri modern portföy yönetimi çatısı altında Markowitz (1952:77-91)'in geliştirdiği yaklaşımdır. Bu yaklaşımda, portföy açısından risk ve getirinin nasıl hesaplanması gerektiği ve oluşturulan portföydeki varlıkların aralarındaki ilişki incelenerek varlık artırım veya azaltımı konusunda bir model önerilmektedir (Deniz ve Okuyan, 2017:1027-1037). Geleneksel portföy yönetimi yaklaşımında ise, her bir varlığın taşımış olduğu risk dikkate alınmadan, portföy içerisindeki menkul kıymet sayısında yapılacak subjektif artışların portföyün riskini düşüreceği görüşü savunulmaktadır.

Portföy çeşitlendirmesi, portföydeki her bir yatırım aracının ayn türden olsa bile, portföyün toplam risk unsurlarının ortalama risk değerine eşit olmaması, portföy riskini azalttığını göstermektedir. (Brealey vd., 2007:245).

\section{Risk ve Getiri}

Riskin belirsizlik içerisinde tahmin edilebilirliği söz konusu olsa da belirli bir ölçü birimi yoktur. Belirsizlik çerçevesinde sonuçlar ne kadar geniş ise karşılaşılacak risk de o kadar büyük olacaktır. Risk, olasılık tahminleri içerisinde, objektif verilere dayalı olarak belirlenir. Finans literatüründe gerçekleşen getiri ile beklenen getiri arasındaki farktır (Basık, 2011:652). Belirsizlik (uncertainty) ise yatırımlar getirilerinin gerçekleşip gerçekleşmeyeceği hakkında herhangi bir verinin olmaması durumudur. Bu noktada, tahminler subjektif veriler üzerinden yapılır (Basık, 2011:746). Kısaca risk, her ne kadar belirsizlik kavramı ile bir tutulsa da, gelecekteki beklenen sonuçlarla karşılaşma olasılığını ve sapmaları ifade eder (Alkin vd., 2001:105).

Riskler sınıflandırıldığında temelde iki tür riskle risk türüyle karşılaşılmaktadır; sistematik risk ve sistemaktik olmayan risk. Sistematik risk politik, sosyal ve ekonomik açıdan dış çevre faktörleri gibi makro düzeyde firmaların risk düzeylerine etki ederken, sistematik olmayan risk, sektörel, yönetim ve faaliyet kolu gibi yalnız firmanın iç yapısından kaynaklanan riski ifade etmektedir (Bolak, 2001:104). Finansal olarak riskler sinıflandırıldığında ise; piyasa riski, kredi riski, likidite riski ve operasyonel risk ile karşılaşılmaktadır. Bu riskler, çeşitli finansal kuruluşlar 
içerisinde yer almakta ve yaptıkları faaliyetlere göre değişmektedir. Bankalar, güvenlik ve finansal sağlamlık adına mevduat ve sigorta fonlarının korunması faaliyetlerinde kredi ve piyasa riski ile aracı kurumlar, müşterileri korumak adına hisse senedi piyasalarının güvenirliğini artırmakla piyasa ve likidite riski ile sigorta şirketleri talep sahiplerini korumakla sigorta ve piyasa riski ile yatırım fonları ise emeklileri ve maaş fonlarını korumakla piyasa ve borç riski ile karşılaşabilmektedir (Gökgöz, 2006:13).

Gerek finansal açıdan gerekse diğer alanlarda riskin yönetilebilmesi, çeşitli analiz yöntemlerindeden faydalanılarak seçim ve karar verme aşamasında mümkün olabilmektedir. Özellikle, riske maruz değer analizleri bu konuda yatırımcıların kararlarına ışık tutmakta, parametrik ve parametrik olmayan analizler başlı̆̆ı altında incelendiğinde tek bir varlığa yatırım veya birden çok yatırımın oluşturduğu portföylerde riskin belirlenebilmesi ve yönetilebilmesinde önemli bir rol oynamaktadır (Demireli ve Taner, 2009:127-148).

Portföy açısından değerlendirildiğinide, risk ölçümü ve getiri hesaplaması yalnızca bir finansal varlığın risk ve getiri oranlarının hesaplamasından daha karmaşık ve zordur. Portföy içerisindeki finansal varlıkların yalnızca kendi risk düzeylerinin ve getirilerinin belirlenmesinden öte, birbirleriyle olan ilişkisini de dikkate almaktadır(Büker vd., 2014:70).Bu konuda, Sharpe (1964:425-442), Lintner (1965:587-615) ve Black (1993:36-38) çalışmalarında menkul kıymetlerin beklenen getirileri ile betaların arasında doğrusal bir ilişki olduğunu ve piyasa betasının risk tahmininde etkili olduğunu belirtmişlerdir.

Modern portföy yaklaşımına göre yalnızca portföydeki varlıkların sayısındaki artırım ile portföy riskinin azaltılması mümkün değildir. Portföylerdeki varlıklar arasındaki ilişkinin de bu noktada dikkate alınması gerekir. Markowitz, geleneksel yaklaşım öncülerinden farklı olarak bu konuda "ortalama - varyans" modelini ortaya koyarak portföyde yer alan varlıkların arasındaki ilişki yönünün ve derecesinin riski azaltma konusunda etkili olduğunu göstermiştir (Kapusuzoğlu ve İbicioğlu, 2013:120).

\section{MENKUL KIYMET YATIRIM ORTAKLIKLARI}

Menkul kıymet yatırım ortaklıkları, çeşitli sermaye piyasası araçlarına, kıymetli madenlere ve diğer finansal araçlara yatırım yapmak suretiyle riski dağıtarak portföy oluşturan, kendi olağan faaliyetlerini gerçekleştirirken bu faaliyetlere dayalı çeşitli giderlere katlanan kollektif kuruluşlar olarak tanımlanmaktadır. En temel fonksiyonu ise, küçük tasarruf sahiplerinin yatırımlarını farklı menkul kıymetlerle çeşitlendirerek portföy oluşturmak ve elde edilen kazancın kar payı olarak ortaklara yatırım oranları üzerinden dağıtmaktır. Diğer yatırım ortaklıklarından farkı ise, sadece sermaye piyasası araçları ile altın ve diğer kıymetli madenlerdeden oluşan bir portföyün yönetilmesi şeklinde sınırlandırılmış olmasıdır. (Sermaye Piyasası Kurulu, 2018).

Yasal açıdan menkul kıymet yatırım ortaklıklarının, mülga 2499 sayılı Sermaye Piyasası Kanunu ile esasları düzenlenmiş olup, faaliyetleri 6362 sayılı Sermaye Piyasası Kanunu hükümleri ile sürdürülmektedir. Her ne kadar, Sermaye Piyasası Kanunu ile genel esasları düzenlenmiş olsa da, anonim şirket olmaları nedeniyle Türk Ticaret Kanunu'nun gerektirmiş olduğu hükümlere uymakla yükümlüdürler (Sermaye Piyasası Kurulu, 2018).

Kollektif ortaklıklar olarak yatırım fonları da bu sınıflandırmanın içerisinde girseler de menkul kıymet yatıım ortkalıkları hukuksal açıdan bağımsız bir tüzel kişiliğe sahipken, yatırım fonları ise kendi tüzel kişiliği olmadan başka bir tüzel kişilik tarafından sözleşme esasına dayalı olarak kurulmakta, fonksiyon ve hizmet açısından birbirlerinden ayrılmaktadırlar. Menkul kıymet yatırım ortaklıkları sabit ve değişken sermayeli olarak iki ayrı tür içerisdinde piyasada yer almaktadır. Gerek sabit gerekse değişken sermayeli olsun kurulacak olan menkul kıymet yatırım 
ortaklıklarının kuruluş, kurucu, paylarının halka arzı, pay devirleri, ortak ve kurucuda aranan nitelikler, yönetim ilkeleri, faaliyet esasları, portföy sınırlamaları, portföyde bulunan varlıkların değerlemesi ve saklanması, pay geri alımları, kamuyu aydınlatma ve yatırımcı bilgilendirme yükümlülükleri, menkul kıymet yatırım ortaklığı statüsünden çıkma, kar payı dağıtımı gibi genel tebliğ esasları 27.05.2015 tarih ve 29368 nolu Resmi Gazete'de yer alan Menkul Kıymet Yatırım Ortaklıklarına İliş̧kin Esaslar Tebliği (III-48.5)'nde yayınlanmıştır (2015).

\section{Sabit Sermayeli Yatırım Ortaklıkları}

Hukuksal olarak anonim şirketi olarak kurulan sabit sermayeli yatırım ortaklıkları, kanun hükümleri uyarınca ve kayıtlı sermaye esasına göre tasarruf sahipleri adına; özelleştirme kapsamına alınanlar dahil Türkiye'de kurulu hisse senedi ihraççılarına ait paylar, özel ve kamu borçlanma araçları, 7.8.1989 tarihli ve 89/14391 sayılı Bakanlar Kurulu Kararı ile yürürlüğe konulan Türk Parasını Kıymetini Koruma Hakkında 32 sayılı Karar hükümleri çerçevesinde alım satımı yapılabilen, yabancı özel sektör ve kamu borçlanma araçları ve ihraççı payları, 12 aydan uzun vadeli olmamak üzere vadeli mevduat ve katılma hesabı, borsada işlem görmeleri kaydıyla; altın veya diğer kıymetli madenler ile bu madenlere dayalı olarak ihraç edilen sermaye piyasası araçları, yatırım fonu katılma payları, repo ve ters repo işlemleri, kira sertifikaları, gayrimenkul sertifikaları, yatırım kuruluşları ve ortaklık varantları ile yatıım kuruluşları sertifikaları, Takasbank para piyasası işlemleri, türev araç işlemlerinin nakit teminatları ve primleri, kurulca portföye alınması uygun görülen özel tasarlanmış yabancı yatırım araçları ve ikraz iştirak senetleri, kurulca portföye alınması uygun görülen diğer yatırım araçları oluşturulacak portföyün menkul kıymetlerini oluşturmaktadır (T.C. Başbakanlık Sermaye Piyasası Kurulu, 2016:4).

\section{Değişken Sermayeli Yatırım Ortaklıkları}

Değişken sermayeli yatırım ortaklıkları ise, sabit sermayeli yatırım ortaklıkları ve yatırım fonlarına kısmen benzemektedir. Sermayesinin açık uçlu olması ve paylarının itibari değerinin bulunmaması ve pay alım satımlarında yalnızca ortaklığın kendisine iade edilmesi şeklinde yapılabilmesidir. Bunun dışında anonim şirket şeklinde kurulmaları ve tüzel kişiliğe sahip olmaları da benzerliklerinin diğer bir boyutudur.

Bu ortaklık türü Türk hukuki yapısında ilk defa yer alan bir sistemi ön plana sürmektedir. Ülkemizde yasal esaslar tamalanmış olmasına rağmen henüz uygulama alanında faaliyet gösteren herhangi bir ortaklık yer almamaktadır. Değişken sermayeli menkul kıymet yatırım ortaklıkları, 30.12.2012 tarih ve 28513 sayılı Resimi Gazete'de yayımlanan 6362 sayılı yeni Sermaye Piyasası Kanunu ile yasal altyapısı oluşturulan düzenlemelerle birlikte Avrupa Birliği Transfer Edilebilir Menkul Kıymetlere Yatırım Yapan Kolektif Yatırım Kuruluşları çerçevesi içerisinde de yer almaya başlamıştır. (Münyas, 2017:147-160).

\section{Menkul Kıymet Yatırım Ortaklıklarının Yönetim İlkeleri}

Etkin bir portföy oluşturmak ve riski düşürmek amacıyla faaliyet sürdüren menkul kıymet yatırım ortaklıklarının doğal bir çeşitlendirme olduğu görüşü üzerine kurulu olarak yapılan bu çalışmada, etkinliğin yönetim ilkelerince desteklendiği düşünülmektedir. Buradaki portföy etkinliği aynı risk seviyesinde bulunan yatırım araçlarının çeşitli birleşimlerinden en iyi getiriyi sağlamak olduğudur (Özdemir ve Giresunlu, 1995:55-60). Menkul kıymet yatırım ortaklıklarının 
yönetim ilkeleri şunlardır (Sermaye Piyasası Kurulu, 2016):

- Riskin Dağıtılması İlkesi: Bireysel yatırım anlamında tasarruf sahiplerinin kendi imkanlarıyla elde edemeyecekleri ölçüde riskin dağıtılması esasına dayanmaktadır. Menkul kıymet yatıım ortaklıkları birçok yatırımcıdan fon elde ederek yüksek tutarlarda portföyler oluşturabilirler. Bu sayede, çok sayıda paya ve sermaye piyasası aracına yatırım yaparak çeşitlendirme yoluna gierler ve pay fiyatlarındaki herhangi bir düşme anında bu durumdan en az etkilenme ihtimalini elde ederler.

- Profesyonel Yönetim: Yüksek piyasa bilgisi ve teknik bilgi gerektirmesi nedeniyle bu ortaklıklar, piyasa hareketlerini gerçeğe en yakın şekilde tahmin etmek ve oluşturulan portföyleri en etkin bir biçimde kullanmakla yükümlüdürler. Bu nedenle, kalifiye çalışanların ortaklıktaki paydaşlara belirli risk düzeylerinde en makul getiriyi elde etmesi beklenir.

- Ortaklıktan Doğan Haklar: bir menkul kıymet yatırım ortaklığında paydaş olmuş tasarruf sahibi birtakım mali ve mali olmayan haklara sahip olmaktadır. Bunun yanı sıra oluşturulan portföy içerisinde işlem yetkisini yönetim tarafına devrederek kendi pay haklarının korunmasına yönelik beklenti içerisinde bulunmaktadırlar.

- Mal Varlığının Korunması: Portföyde yer alan varlıklar kurucu ortak ve portföy yöneticilerinden ayrı bir yerde muhafaza edilmektedir. Bu varlıklar, portföy saklayıcısı tarafından yapılacak olan bir sözleşme ile koruma altına alınır.

Bu bağlamda, yatırım ortaklıkları faaliyetleri itibariyle incelendiğinde riski makul seviyelerde tutması, alternatif yatırımlar içerisinde değerlendirilmesi noktasında uygun bir seçenek olarak karşımıza çıkmaktadır. Buradan yola çıkarak, menkul kıymet yatırım ortaklığı sektör endeksinin, diğer sektör endekslerine göre riskinin daha düşük olup olmadığı uygulama kısmında ele alınmıştır.

\section{SEKTÖR ENDEKSLERINIIN RİSK VE GETİRİ HESAPLAMALARI}

Borsa İstanbul'da yer alan firmaların sektörel çeşitliliği oldukça fazladır. Bu kapsamda sektörler, faaliyet alanlarına göre bir endeks çatısı altında toplanmaktadır. Böylece, firmaların bulundukları sektörün genel durumu gözlemlenebilmekte ve analiz süreci içerisinde değerlendirmeye olanak sağlayabilmektedir. Sektör çeşitliliğinin fazla olması, yatırım yapılacak sektör seçimini zorlaştırmaktadır. $\mathrm{Bu}$ nedenle, sektörleri birbiriyle karşılaştırmak, yatırım tercihlerini şekillendirmede önemli bir faktör olarak karşımıza çıkmaktadır. Bunun yanı sıra, sektörlerin kendi içerisinde taşımış oldukları riskleri kıyaslamak ve bu doğrultuda riskin azaltılmasına yönelik portföy oluşturmak diğer bir alternatif olarak kullanılabilmektir. Bu çalışmanın uygulamasında, sektörlerin bireysel risklerinin doğal bir çeşitlendirme olarak kabul edebileceğimiz menkul kıymet yatırım ortaklıklarının taşımış olduğu risk ile karşılaştırması yapılmıştır.

\section{Araştırmanın Veri Seti}

Araştırmada kullanılan Borsa İstanbul sektör bazlı endeks verileri, Foreks FX Plus yazılımı aracılığıyla elde edilerek 2008-2017 yılları arasında aylık periyotlarla sınıflandırılmıştır. 22 ayrı sektör endeksi ile menkul kıymet yatırım ortaklığı endeksi verileri alınmış, pazar endeksi olarak BİST 100 fiyat endeksi verileri kullanılmıştır. Esas alınan sektörler, menkul kıymet yatırım ortaklıkları endeksi ve BIST 100 endeksinin aylık sektör getirileri hesaplanmıştır. Karşılaştırma ölçüsü olarak standart sapma, varyans, değişim kat sayısı, kovaryans ve beta katsayıları hesaplanmiştır.

\section{Araştırmanın Yöntemi}


İstatistiksel hesaplamalardan elde edilmiş bilgiler doğrultusunda, sektör endekslerinin verileri ile menkul kıymet yatırım ortaklıklıları endeksinin verileri karşılaştırma yapılarak yorumlanmıştır. Bu kısımda, standart sapma ve varyans portföy yönetimi açısından riski ifade etmektedir (Demirtaş ve Güngör, 2004:103-109). Çalışmada elde edilen standart sapma ve varyans verileri şu formüllerden elde edilmiştir (Ceylan, 2015):

$\sigma_{i}^{2}=\sum_{j=1}^{n} \frac{\left[\left(R_{i j}-E\left(R_{i}\right)\right]^{2}\right.}{n} \quad$ veya $\sigma_{i}^{2}=\sum_{j=1}^{n} P_{i j}\left[\left(R_{i j}-E\left(R_{i}\right)\right]^{2}\right.$

Formülleriyle tanımlanabilir. Formüllerdeki $\mathbf{P}_{\mathrm{ij}}$ olasılık değerini, $\mathbf{R}_{\mathrm{ij}}$ getiriyi, $\mathbf{E}(\mathbf{R})$ ise beklenen getiriyi göstermektedir. Kısaca, her bir yatırımın olasılık dağılımına göre gerçekleşebilecek getiri ile bu yatırımdan beklenen getirinin farklarının karesi alınmakta, her bir ihtimalin olasılık değeri ile ağırlıklandırılmaktadır. Varyans ( $\sigma^{2}$ veya VAR), bir değişkenin kendi ortalamasına göre ne kadar uzak veya yakın değerler aldığını gösteren bir ölçüttür. Standart sapma $(\sigma)$ ise varyansın kareköküdür. Standart sapma, varyanstan farklı olarak kullanılan veri setinin asıl birimini ifade etmektedir. Beta katsayısı ise, incelenecek olan hisse senedinin piyasaya olan duyarlılığını göstermekte ve şu şekilde hesaplanmaktadır (Ercan vd., 2007:295-324):

$\beta_{i, m=\frac{\operatorname{Cov}_{i, m}}{\operatorname{Var}_{m}}}$

$\beta=1$ ise, ilgili varlığın piyasa ile benzer risk düzeyine,

$\beta<1$ ise, ilgili varlığın piyasadan daha düşük risk düzeyine,

$\beta>1$ ise, ilgili varlığın piyasadan daha yüksek risk düzeyine sahip olduğu anlaşılır.

Bir başka ifade ile beta katsayısı, aynı zamanda sistematik riskin bir ölçüsüdür. Bu katsayının yüksek olması riskin de yüksek olduğu, düşük olması riskin de düşük olduğunu ifade etmektedir.

\section{Araştırmanın Bulguları}

BİST sektörlerinin ve menkul kıymet yatırım ortaklığı sektör endeksi bulguları karşılaştırılmış, standart sapma ve varyans değerleri yardımıyla risk düzeyleri belirlenmiştir. Buna bağlı olarak beta katsayısı piyasanın değişimine olan duyarlılığını veya sistematik risk düzeyini temsil etmektedir. Tablo-1'de veri setlerinden elde edilmiş sektör ve BIST 100 endeks analiz bilgileri yer almaktadir.

Yapılan analiz neticesinde, sektörel endekslerden riskin ölçüsü olan standart sapmanın en yüksek olanı 0,1184 seviyesinde spor endeksi, 0,1111 seviyesinde de ulaştırma endeksi risk seviyesinin BİST sektör endeksleri arasında en üst noktalarını göstermektedir. Standart sapma katsayısına göre risk seviyesinin en düşük olanlar 0,0673 ile gıda sektörü, 0,0657 ile sinai endeks ve 0,0647 seviyesinde menkul kıymet yatırım ortaklıkları endeksleridir. Bu sayede, menkul kıymet yatırım ortaklığı endeksi riskinin doğal bir çeşitlendirme unsuru olması itibariyle tek bir faaliyet alanında hizmet veren sektörlere göre riskinin düşük olması nedeniyle yatırım tercihleri arasında bulundurulabileceği anlaşılmıştır.

Beta katsayısının belirtilen referans değerlerine göre $(\beta=1, \beta<1$ ve $\beta>1)$ sonuçlar incelendiğinde, çeşitlendirmenin olmadığı sektörlerin riskleri menkul kıymet yatırım ortaklığının mevcut risk ve getiri düzeyinden daha yüksek çıktığı görülmektedir. $\beta=1^{\prime}$ e göre yaklaşı olarak 1,0179 değerinde metal eşya makine endeksi ile 1,0262 değerinde ulaştırma sektörü yer almaktadır. $\beta>1$ 'e göre 1,2705 değeri ile bankacılık sektörü ardından 1,1854 ile mali sektör endeksi yer almaktadır. Son olarak $\beta<1$ seviyesinde 0,5346 değeri ile menkul kıymet yatırım ortaklığ 1 endeksi çalışmanın amacını destekler ölçüde en düşük olarak karşımıza çıkmaktadır. 
Tablo 1. Risk ve Getiri Açısından Sektörel Endeks Bulguları

\begin{tabular}{|l|l|l|l|l|}
\hline Sektör & Varyans & Standart Sapma & Kovaryans & Beta \\
\hline XBANK & 0,0100 & 0,0999 & 0,0072 & 1,2705 \\
\hline XBLSM & 0,0089 & 0,0946 & 0,0037 & 0,6574 \\
\hline XELKT & 0,0097 & 0,0983 & 0,0052 & 0,9217 \\
\hline XFINK & 0,0087 & 0,0933 & 0,0049 & 0,8724 \\
\hline XGIDA & 0,0045 & 0,0673 & 0,0036 & 0,6342 \\
\hline XGMYO & 0,0072 & 0,0847 & 0,0050 & 0,8949 \\
\hline XILTM & 0,0046 & 0,0681 & 0,0034 & 0,6028 \\
\hline XKAGT & 0,0080 & 0,0896 & 0,0043 & 0,7679 \\
\hline XKMYA & 0,0054 & 0,0738 & 0,0046 & 0,8227 \\
\hline XKURY & 0,0058 & 0,0759 & 0,0055 & 0,9687 \\
\hline XMANA & 0,0087 & 0,0934 & 0,0047 & 0,8296 \\
\hline XMESY & 0,0077 & 0,0878 & 0,0057 & 1,0179 \\
\hline XSGRT & 0,0076 & 0,0872 & 0,0051 & 0,9091 \\
\hline XSPOR & 0,0140 & 0,1184 & 0,0040 & 0,7052 \\
\hline XTAST & 0,0047 & 0,0684 & 0,0040 & 0,7167 \\
\hline XTCRT & 0,0048 & 0,0691 & 0,0036 & 0,6427 \\
\hline XTEKS & 0,0060 & 0,0775 & 0,0037 & 0,6647 \\
\hline XTRZM & 0,0082 & 0,0904 & 0,0041 & 0,7308 \\
\hline XULAS & 0,0123 & 0,1111 & 0,0058 & 1,0262 \\
\hline XUMAL & 0,0083 & 0,0911 & 0,0067 & 1,1854 \\
\hline XUSIN & 0,0043 & 0,0657 & 0,0045 & 0,7927 \\
\hline XUTEK & 0,0074 & 0,0863 & 0,0042 & 0,7387 \\
\hline XYORT & $\mathbf{0 , 0 0 4 2}$ & $\mathbf{0 , 0 6 4 7}$ & $\mathbf{0 , 0 0 3 0}$ & $\mathbf{0 , 5 3 4 6}$ \\
\hline XU100 & 0,0056 & 0,0751 & & \\
\hline & & & & \\
\hline
\end{tabular}

\section{SONUÇ}

Tasarruf sahipleri, sermaye piyasalarının gelişmesi ve teknolojinin de destek faaliyet hizmeti sunması ile birlikte yatırım seçeneğine sahip olmuşlardır. Bu alternatifler arasında yatırımcı beklentisi ile orantılı olarak tercihler yapılabilmektedir. Burada en önemli unsur, yatırımcının risk ve getiri beklenti düzeyidir. Bu doğrultuda birçok yatırımcı, yatırımlarının risk ve getiri düzeyini iyileştirmek için portföy oluşturma yoluna gitmektedir. Risk seviyesini düşük tutmak isteyen yatırımcılar için portföy oluşturmak tek bir menkul kıymete yatırım yapmaya göre daha iyi bir alternatif olarak karşımıza çıkmaktadır.

Çalışmanın amacı ile bağlantılı olarak menkul kıymet yatırım ortaklıkları endeksinin $(\beta X Y O R T=0,5346)$ diğer sektör endekslerine göre ( $\beta$ XBANK=1,2705, $\beta X U M A L=1,1854)$ doğal bir çeşitlendirme unsuru olduğunu ispatlar şekilde, riskinin daha düşük olduğu ortaya çıkmıştır. Dolayısıyla risk almaktan kaçınan ancak, sermaye piyasalarında düşük risk seviyeli yatırım yapmak isteyen yatırımcılar için menkul kıymet yatırım ortaklıklarının alternatif bir yatırım seçeneği olabileceği görülmektedir.

Bilineceği üzere, Türkiye'de genel olarak finansal okuryazarlık seviyesi oldukça düşüktür. Bunun sonucunda, finansal piyasalarda yatırım yapan yatırımcıların önemli ölçüde bir bilgi ve amaç eksikliği içerisindedir. Bu durum, bireysel yatırımcıların finansal piyasalarda büyük bir riske maruz kalmalarına neden olmakta ve özellikle hisse senedi piyasasında büyük mağduriyetlere neden olmaktadır. Bu çalışmanın sonuçları, tek başına herhangi bir sektördeki hisse senetlerine yatırım yapmak yerine, çeşitlendirme unsuru içeren menkul kıymet yatırım 
ortaklıklarına yatırım yapmanın tecrübesiz yatırımcıların maruz kalacağı riskleri önemli ölçüde azaltabileceğini çok net olarak göstermiştir.

$\mathrm{Bu}$ çalışmanın, riskten kaçınma durumlarına göre farklı tercihlere sahip yatırımcılara yol gösterme ve bir sonraki menkul kıymet yatırım ortaklıkları alanında çalışılacak konularda yardımcı olması açısından önemli olduğu düşünülmektedir.

\section{KAYNAKÇA}

Abay, R. (2013). Markowitz Karesel Programlama İle Portföy Seçimi: İMKB 30 Endeksinde Riskli Portföylerin Seçimi. Ç.Ü. Sosyal Bilimler Enstitüsü Dergisi, 22(2): 175-194.

Aksoy, E. E. (2014). Uluslararası Portföy Yönetimi (1. Basım). Ankara: Detay Yayıncılık.

Alkin, E., Savaş, T. ve Akman, V. (2001). Bankalarda Risk Yönetimine Giriş. İstanbul: Çetin Matbaacilik.

Basık, F. O. (2011). Ansiklopedik Muhasebe ve Finans Terimleri Sözlüğü (1. Basım), İstanbul: Türkiye İş Bankası Kültür Yayınları.

Black, F. (1993). Estimating Expected Returns. Financial Analysts Journal, 49: 36-38.

Bolak, M. (2001). Sermaye Piyasası, Menkul Kıymetler ve Portföy Analizi (4. Basım). İstanbul: Beta Yayıncilik.

Brealey, R. A., Myers, S. C. ve Marcus, A. J. (2007). İşletme Finansının Temelleri. (Çeviren, Bozkurt Ü., Arıkan T. ve Doğukanlı H.) İstanbul: Literatür Yayıncılık.

Brigham, E. F. and Houston, J. F. (1996). Fundamentals of Financial Management. Florida: The Dryden Press Harcourt Brace College Publishers.

Büker, S., Aşıkoğlu, R. ve Sevil, G. (2014). Finansal Yönetim. Ankara: Sözkesen Matbaacılık.

Ceylan, O. (2015). Portföy Yönetiminde Risk Ölçüsü: Varyans ve Standart Sapma Nedir? Piyasa Rehberi: http://piyasarehberi.org/yatirim/portfoy-yonetimi/164-varyans-ve-standartsapma> [Erişim Tarihi: 12.07.2018]

Demireli, E., ve Taner, B. (2009). Risk Yönetiminde Riske Maruz Değer Yöntemleri ve Bir Uygulama. Süleyman Demirel Üniversitesi İktisadi ve İdari Bilimler Fakültesi Dergisi, 14(3): 127-148.

Demirtaş, Ö. ve Güngör, Z. (2004). Portföy Yönetimi ve Portföy Seçimine Yönelik Uygulama. Havacilik ve Uzay Teknolojileri Dergisi, 1(4): 103-109.

Devran, D. ve Okuyan, H. A. (2017). Geleneksel ve Modern Portföy Yönetiminin Ampirik Sonuçlarının Karşılaştırışması: BİST Uygulaması. Uluslararası Katılımlı 21. Finans Sетроzуити (s. 1027-1037). Balıkesir: Balıkesir Üniversitesi.

Ercan, M. K., Öztürk, M. B., Küçükkaplan, İ., Başcı, E. S. ve Demirgüneş, K. (2007). Halka Açık Firmaların Beta Katsayılarının Regresyon Modeli ile Tespiti ve Halka Açı Olmayan Firmalara Ynelik Uygulanabilirliği. Dokuz Eylül Üniversitesi İktisadi ve İdari Bilimler Fakültesi Dergisi, 22(2): 295-324.

Gitman, L. J. (1992). Basic Managerial Finance. New York: Harper Collins Publishers. 
Gökgöz, E. (2006). Riske Maruz Değer (VaR) ve Portföy Optimizasyonu. Ankara: Sermaye Piyasası Kurulu Yayın No. 190.

Kapusuzoğlu, A. ve İbicioğlu, M. (2013). Portföy Çeşitlemesi: İMKB'de Sektörel Endeksler Üzerine Bir Analiz. Muhasebe ve Finansman Dergisi, (58): 119-138.

Klapper, L., Lusardi, A. and Oudheusden, P. V. (2014). S\&P Global Finlit Survey. Global Financial Literacy Excellence Center: https:/gflec.org/wp-content/uploads/2015/11/3313Finlit_Report_FINAL-5.11.16.pdf?x98192> [Erişim Tarihi: 10.02.2019]

Lintner, J. (1965). Security Prices, Risk and Maximal Gains from Diversification. Journal of Finance, 20(4): 587-615.

Markowitz, H. (1952). Portfolio Selection. The Journal of Finance, 1(7): 77-91.

Münyas, T. (2017). Türk Sermaye Piyasasının Yeni Kolektif Yatırım Kuruluşu: Değişken Sermayeli Menkul Kıymet Yatırım Ortaklığı'nın Yapı, İşleyiş ve Faaliyet Esasları Üzerine Bir İnceleme. Maliye Finans Yazıları, (107): 147-160.

Özdemir, E. ve Giresunlu, İ. M. (1995). Sharpe Tek İndeks Modeli ile Portföy Seçimi. Yönetim Dergisi(21): 55-60.

Resmi Gazete. (2015, Mayıs 27). Menkul Kıymet Yatırım Ortaklarına İlişkin Esaslar Tebliği. (29368).

Sermaye Piyasası Kurulu. (2018). Menkul Kıymet Yatırm Ortaklikları Tanıtım Rehberi. T.C. Başbakanlık Sermaye Piyasası Kurulu: http://www.spk.gov.tr/Sayfa/AltSayfa/377 [Erişim Tarihi: 26.06.2018]

Sharpe, W. F. (1964). Capital Asset Prices: A Theory of Market Equilibrium Under Conditions of Risk. The Journal of Finance, 19(3): 425-442.

T.C. Başbakanlık Sermaye Piyasası Kurulu. (2016). Menkul Kıymet Yatırım Ortkalıkları. (2. Basım) Ankara: Tuna Dijital. 